\title{
THE STUDY OF DRUG INDUCED HEPATOTOXICITY IN ATT PATIENTS ATTENDING IN NATIONAL TUBERCULOSIS CENTER IN BHAKTAPUR
}

\author{
Khadka J, ${ }^{1}$ Malla $\mathrm{P}_{,}{ }^{2}$ Jha SS, ${ }^{3}$ Poudel $\mathrm{SR}^{4}$ \\ ${ }^{1}$ Sr. Medical Technologist. (Microbiologist), WRH, Pokhara \\ ${ }^{2}$ Consultant chest physician, Director, NTC, Bhaktapur, Thimi \\ ${ }^{3}$ Sr. Medical Officer, NTC, Bhaktapur, Thimi \\ ${ }^{4}$ Medical Officer. Padma Nursing Home, Pokhara
}

\begin{abstract}
The drug-induced hepatotoxicity is a significantly increasing problem worldwide, but it is of more concern in the treatment of tuberculosis (TB) infection, especially in a third world country like Nepal, where tuberculosis is still endemic. Liver has a central role in drug metabolism and detoxification, and is consequently vulnerable to toxic effects of the drugs. The study was carried out from August 2006 to May 2007. The ATT patients, who visited the chest clinic, were sent to the laboratory for analysis of Liver enzymes (ALT, AST) and bilirubin level. During the period of August 2006 to May 2007 total of 114 patients; 114 blood samples were collected for liver enzymes analysis. It was found that among114 ATT patients; 41 patients (35.0\%) had abnormal parameters with the elevation of serum bilirubin level, AST level and ALT level. It showed that drug induced hepatotoxicity due to anti TB drugs is relatively higher rate among lower socio-economic status group. Out of 114 cases, the marked elevation of total bilirubin level (>5.0mg/dl) was found in $15(13.0 \%)$ and mild elevation of bilirubin level (1.1-5.0mg/dl) was found in $25(22.0 \%)$ patients while $74(65.0 \%)$ patients were found to have normal level of bilirubin. Similarly, 17 (15.0\%) patients were found to have moderate elevation of ALT level (above 51.0IU/L), 5 (4.0\%) patients were found to have slight elevation of ALT level (36-50IU/L) and 92(81.0\%) patients had normal level. Likewise $10(9.0 \%)$ patients were found to have moderate elevation of AST level (above 51.0IU/L); $8(7.0 \%)$ had slight elevation of AST level (41-50 IU/L); and $96(84.0 \%)$ were found to have normal level. The facts associated behind these findings are probably poverty, malnourishment, alcohol consumption, illiteracy of people and poor health management system. Hence, for the treatment of TB, with ATT regimens, a baseline laboratory testing and monitoring system should be adopted before starting treatment which might help to reduce drug induced hepatotoxicity in ATT patients.
\end{abstract}

Keyword : ATT patient, Rifampicin, Ethambutol, Hepatotoxicity, AST, ALT, Enzymes.

\section{INTRODUCTION}

Tuberculosis is one of the major causes of morbidity and mortality here in Nepal and most other poor countries and so is the drugs related

hepatotoxicity associated with the treatment of tuberculosis. Liver has a central role in drug metabolism and detoxification,

\section{Correspondence to}

Mr. Jagat Khadka

Senior Medical Technologist(Microbiologist)

Western Regional Hospital

Dept. Clinical Laboratory

Ramghat, Pokhara, Nepal

Email:khadkajagat@hotmail.com and is consequently vulnerable to the toxic effects of the drugs. The pathogenesis and types of hepatotoxicity are presented, ranging from hepatic adaptation to hepatocellular injury. However the knowledge of the metabolism of anti-TB medications and of the mechanisms involved in hepatotoxicity by ATT is still incomplete.

Structure and function of Liver: The liver is situated between the alimentary tract and the systemic circulation to maximize processing of absorbed nutrients and to minimize exposure of the body to concentration of exogenous substances and their metabolites.

Hepatic Drug Metabolism Transporters, Enzymes, and Excretion: The splanchnic circulation carries ingested 
drugs directly into the liver, a phenomenon known as the "first pass" through the liver. Metabolic enzymes convert these chemicals through phase 1 pathways of oxidation, reduction, or hydrolysis, which are carried out principally by the cytochrome p450 class of enzymes. Phase 2 pathways include glucuronidation, sulfation, acetylation, and glutathione conjugation to form compounds that are readily excreted from the body. Other subsequent steps include deacetylation and deamination. Many drugs may be metabolized through alternative pathways. In phase 3 pathways, cellular transporter proteins facilitate excretion of these compounds into bile or the systemic circulation. Transporter and enzymes activities are influenced by endogenous factors such as circadian rhythms, hormones cytokines, disease states, genetic factors, sex, age, ethnicity and nutritional status, as well as by exogenous drugs or chemicals. ${ }^{1}$

Pathogenesis of drug-induced hepatotoxicity: This may be result from direct toxicity of the primary compound, a metabolite, or from an immunologically mediated response, affecting hepatocytes, billiary epithelial cells, and or liver vasculature. In many cases, exact mechanism and factors contributing to liver toxicity remain poorly understood. Predictable drug induced hepatotoxicity is generally characterized by certain dose - related injury in experimental animal models, has a higher attack rate, and tend to occur rapidly. Injurious free radicals cause hepatocyte necrosis in zones farthest from the hepatic arterioles, where metabolism is greatest and oxidant detoxifying capacity is the least.

Unpredictable reactions comprise most types of drug induced hepatotoxicity. These hypersensitivity or metabolic reactions occur largely independent of dose and relatively rarely for each drug, and may result in hepatocellular injury and or cholestasis. Hepatocyte necrosis is often distributed throughout hepatic lobules rather than being zonal, as is often seen with predictable drug-induced hepatotoxicity. ${ }^{2}$ In hypersensitivity reactions, immunogenic drug or its metabolites may be free or covalently bound to hepatic proteins, forming haptens or neoantigens. Antibody dependent cytotoxic, T-cell, and occasionally eosinophilic hypersensitivity responses may be evoked. Released tumor necrosis factor-alpha, interleukin (IL)-12, and IFNgamma promote hepatocellular programmed cell death (apoptosis), an effect opposed by IL-4, IL-10, IL-13, and monocyte chemo tactic protein-1.

Metabolic idiosyncratic reactions may result from genetic or acquired variation in drug biotransformation pathways, with synthesis or abnormally slow detoxification of a hepatotoxic metabolite.

Drug-induced hepatotoxicity may occur with all currently recommended regimens for the treatment of tuberculosis infection including isoniazid, rifampicin, pyrazinamide and ethambutol. Among four drugs, isoniazid rifampicin pyrazinamide play major role to cause hepatotoxicity.

\section{Mechanism of liver toxicity}

By isoniazid : Normally isoniazid is cleared mostly by the liver, primarily by acetylation by $\mathrm{N}$-acetyl transferase2 (NAT-2). Acetyl-isoniazid is metabolized mainly to monoacetyl hydrazine (MAH) and to the no toxic diacetyl hydrazine, as well as other minor metabolites. The reactive metabolites of monoacetyl hydrazine (MAH) are probably toxic to tissues through free radical generation. The additional isoniazid metabolites acetyl hydrazine covalently binds to liver macromolecules, a process mediated by microsomal enzyme. ${ }^{3}$

By Rifampicin : Rifampicin may occasionally cause dose dependent interference with bilirubin uptake resulting in subclinical, unconjugated hyperbilirubinemia or jaundice without hepatocellular damage. Conjugated hyperbilirubinemia probably is caused by rifampicin inhibiting the major bile salt exporter pump. ${ }^{4}$ Asymptomatic elevated bilirubin may also result from dose-depended competition with bilirubin for clearance at sinusoidal membrane or from impeded secretion at the canalicular level. ${ }^{5}$

By Pyrazinamide : It may exhibit both dose dependent and idiosyncratic hepatotoxicity. Pyrazinamide alters nicotinamide acetyl dehydrogenase levels in liver ${ }^{6}$ which might result in generation of free radical species. There may be shared mechanisms of injury for isoniazid and pyrizinamide, because there is some similarity in molecular structure. Patients who previously had hepatotoxic reactions with isoniazid have more severe reaction with rifampicin and pyrazinamide.

By Ethambutol : There has been one report of ethambutol related liver cholestatic jaundice with unclear circumstances.

\section{METHODOLOGY}

The ATT patients who come to NTC from different DOTS clinics for follow-up visit and monitoring of the DOTS 
treatment were taken into the study. The study was carried out from August 2006 to May 2007. The ATT patients visited to the chest clinic were sent to the laboratory for analysis of Liver enzymes (ALT, AST) and bilirubin level. During the period of August 2006 to May 2007, total of 114 patients were received from the OPD clinic for Liver enzymes analysis in the clinical lab. Blood samples were collected from the patients and serum was separated. The liver enzymes Alanine transaminase (ALT), Aspartate transaminase (AST) and Bilirubin analysis were done. The ALT and AST were analyzed by kinetic method using semi auto analyzer and bilirubin was analyzed by color end point method using semi autoanalyser. The control sample was also used for monitoring each steps of procedure and analyzer machine.

\section{RESULT}

Out of 114 patients, 62 were male and 52 were female. Among the age group, 18(15.7\%) were under $20 \mathrm{yrs}$, $61(53.5 \%)$ were $21-40 \mathrm{yrs}, 31(27.1 \%)$ were $41-60 y e a r$ of age and $4(3.5 \%)$ were above 60year age.

\begin{tabular}{|lrrrr|}
\multicolumn{5}{|c|}{ Table 1: Age and sex group of ATT patients } \\
\begin{tabular}{|l} 
Age groups \\
(yrs)
\end{tabular} & $\begin{array}{l}\text { Sex } \\
\text { Male }\end{array}$ & Female & \multicolumn{1}{l}{ Total } & Percentage \\
$<20$ & 9 & 9 & 18 & $15.7 \%$ \\
\hline $21-40$ & 32 & 29 & 61 & $53.5 \%$ \\
$41-60$ & 18 & 13 & 31 & $27.1 \%$ \\
$>60$ & 3 & 1 & 4 & $3.5 \%$ \\
\hline Total & 62 & $\mathbf{5 2}$ & 114 & $\mathbf{1 0 0 . 0} \%$ \\
\hline
\end{tabular}

Out of total 114 patients, $41(35 \%)$ showed abnormal pattern of liver function, i.e. elevation of serum bilirubin, serum alinine transaminase (ALT) and serum aspartate transaminase (AST). $73(65 \%)$ showed normal pattern of the liver function; i.e. normal level of S. bilirubin, alanine transaminase (ALT), aspartate transaminase (AST).

\begin{tabular}{|lrrc|}
\hline \multicolumn{4}{|c|}{ Table 2: Pattern of liver function } \\
\hline Age group & $\begin{array}{r}\text { Normal } \\
\text { pattern }\end{array}$ & $\begin{array}{c}\text { Abnormal } \\
\text { pattern }\end{array}$ & Total \\
$0-20$ & $11(61.1 \%)$ & $7(38.8 \%)$ & $18(100.0 \%)$ \\
$21-40$ & $42(68.9 \%)$ & $19(31.1 \%)$ & $61(100.0 \%)$ \\
$41-60$ & $17(54.9 \%)$ & $14(45.1 \%)$ & $31(100.0 \%)$ \\
$>60$ & $3(75.0 \%)$ & $1(25.0 \%)$ & $4(100.0 \%)$ \\
\hline Total & $73(65 \%)$ & $41(35 \%)$ & $114(100 \%)$ \\
\hline
\end{tabular}

Out of 114 ATT patients, the bilirubin level was found to be greater than $5.0 \mathrm{mg} / \mathrm{dl}$ in $15(13.0 \%)$ patients; bilirubin level of $1.5-5.0 \mathrm{mg} / \mathrm{dl}$ was found in $25(22.0 \%$ ) patients and $74(65.0 \% \%)$ patients had normal bilirubin level. Similarly, $17(15.0 \%)$ patients had moderate elevation of ALT level (>51.0 IU/L); $5(4.0 \%$ ) patients had slight elevation of ALT level ranging from $36-50 \mathrm{IU} / \mathrm{L}$ and $92(81.0 \%)$ patients were found to have their ALT level within the normal range.

Meanwhile, 10 ( $9.0 \%$ ) patients turned out to have moderate elevation of AST level (>51.0 IU/L) and 8(7.0\%) were found to have slight elevation of AST level ranging from 41.0$50.0 \mathrm{IU} / \mathrm{L}$; and 96 (84.\% ) patients had their AST level within normal range.

\begin{tabular}{|lll|}
\hline \multicolumn{3}{|c|}{ Table 3: Result of bilirubin parameters } \\
\hline $\begin{array}{l}\text { Range of Bilirubin level, } \\
\mathrm{mg} / \mathrm{dl}\end{array}$ & $\begin{array}{l}\text { No. of } \\
\text { patients }\end{array}$ & Percentage \\
$\begin{array}{l}\text { 0.1-1.0 (normal range) } \\
\text { 1.1-5.0 (mild increase) }\end{array}$ & 74 & $65.0 \%$ \\
$\begin{array}{l}\text { >5.0 (moderate } \\
\text { increase) }\end{array}$ & 15 & $22.0 \%$ \\
\hline Total & $13.0 \%$ \\
\hline
\end{tabular}

\begin{tabular}{|lcc|}
\multicolumn{3}{|c|}{ Table 4: ALT parameter } \\
\hline Range of ALT (IU/L) & $\begin{array}{c}\text { No. of } \\
\text { patients }\end{array}$ & Percentage \\
$<35.0$ (normal range) & 92 & $81.0 \%$ \\
$\begin{array}{l}36.0-50.0 \text { (mild } \\
\text { increase) }\end{array}$ & 5 & $4.0 \%$ \\
$>51.0$ (moderate & 17 & $15.0 \%$ \\
increase) & 114 & $100.0 \%$ \\
\hline Total & & \\
\hline
\end{tabular}

\begin{tabular}{|lcc|}
\hline \multicolumn{3}{|c|}{ Table 5: AST parameter } \\
\hline \multicolumn{1}{|c|}{$\begin{array}{l}\text { Range of AST } \\
\text { (IU/L) }\end{array}$} & $\begin{array}{c}\text { No. of } \\
\text { patients }\end{array}$ & Percentage \\
$\begin{array}{l}<40.0 \text { (Normal } \\
\text { range) }\end{array}$ & 96 & $84.0 \%$ \\
$\begin{array}{l}41.0-50.0 \text { (mild } \\
\text { increase) } \\
>51.0 \text { (moderate }\end{array}$ & 8 & $7.0 \%$ \\
increase) & 10 & $9.0 \%$ \\
\hline Total & 114 & $100.0 \%$ \\
\hline
\end{tabular}

\section{DISCUSSION}

As per the results, it was found that among 114 ATT patients $41(35.0 \%)$ had abnormal parameters with the elevation of 
serum bilirubin level, AST level and ALT level. It showed that drug induced hepatotoxicity due to anti TB drugs is relatively higher among the low income status compared to general literature and data's suggestion. ${ }^{7}$. The probable causes behind these findings could be poor nutrition, alcohol consumption, HIV co-infection many more. Each factor should be taken into account before definitive conclusions can be drawn, however it is beyond the scope of this study to establish cause and affect relationship with various above mentioned factors. Several studies suggested that increasing age is a risk factor for TB drugs induced hepatotoxicity but statistical significant was not achieved. One study reported hepatotoxicity rate ranging from 2.0 to $8.0 \%$ as age increased, with an average ${ }^{8}$ of $5.0 \%$. Other studies have reported that hepatotoxicity ranges from 22.0 to $33.0 \%$ in those older than 35 years. Out of 114 cases, age group ranging from 41-60 yrs had the greatest prevalence $(45 \%)$ of abnormal liver function parameters, while the rates of abnormal liver parameters in age group $<20$ and $20-40$ yrs. were similar and the age group $>60$ yrs. contributed least to the percentage of the patient with abnormal liver parameters, namely elevated AST, ALT and Bilirubin. Out of 114 patients, almost $35 \%$ of patient had abnormal bilirubin level with $13 \%$ out of the total patients having marked elevation of bilirubin. Meanwhile more than $80 \%$ of the patients had normal level of AST and ALT level and only $15 \%$ and $10 \%$ had markedly elevated AST and ALT level respectively. At the same time, related literature shows overall risk of hepatotoxicity ranges from 5\%-33\% in those undergoing TB treatment, with rate increasing as the age of patients under treatment increases. ${ }^{9}$ Similarly, it is shown in other study that in children younger than 5 yrs, with extra pulmonary TB including TB meningitis treated with Isoniazid, Rifampicin and Pyrazinamide, more than $82 \%$ had ALT of more than $100 \mathrm{IU} / \mathrm{L}$ and more than $40 \%$ developed asymptomatic hepatitis. ${ }^{10}$ Several studies also reported increased risk of hepatotoxicity in women especially pregnant one..$^{11,12}$ Likewise in alcohol user, several studies have indicated that alcohol use also induce the hepatotoxicity in ATT patients. ${ }^{13,14}$ Other associated factors include malnutrition or hypoalbuminemia, HIV infection, Hepatitis B infection, Hepatitis C infection and second line ATT drugs conditions. Although in Nepal, there is hardly $2.5 \%$ of TB- HIV co-infection reported and association of TB and Hepatitis B and C infection and HIV infection has not been studied and reported in Nepal, their importance and significance can't be over emphasized.

\section{CONCLUSION}

Overall, drug induced hepatotoxicity in ATT patient was found to be higher than $34 \%$, however, the age , sex , disease conditions, nutrition status, alcohol abuse and other possible confounding factors play statistically significant role. The reasons behind this higher level of drug induced hepatotoxicity are probably poverty, malnourishment, alcohol consumption, illiteracy of people and poor health management system with age playing a significant role. For better cause and effect relationship with less bias and for clinical significance, a broader, controlled cohort study of larger size is recommended. For now, with an effective DOTS program accessible all over the country, a baseline laboratory testing criteria and monitoring system should be adopted before starting treatment to effectively reduce the treatment related morbidities. ${ }^{15}$. Along with this patient and staff education, appropriate selection of patients for treatment, careful regimen selection and monitoring will minimize the associated risk and adverse effects. The ability to adapt to changing medical landscape will be crucial to continue safe and effective treatment of TB.

\section{REFERENCES}

1. Lee J, Boyer JL. Molecular alteration in hepatocyte transport. Semin Liver Dis 2000:20:373-84.

2. Gronhagen-Riska C., Hellstrom P.E., Froseth B. Predisposing factors in hepatitis induced by isoniazid-rifampicin treatment of tuberculosis. Am Rev Respir Dis 1978; 118:461-66

3. Mitchel J.R., Thorgeirsson U.P., Black M., Timbrel J.A., Snodgrass W.R., Potter W.Z., Jellow H.R., Keiser H.R. Incidence of isoniazid hepatitis in rapid acetylates: possible relation to hydrazine metabolites. Clin Pharcol Ther 1975; 18:70-79.

4. Byrne J.A., Straunieks S.S., Mieli-Vergani G., Higgins C.F., Linton K.J., Thompson R.J., The human bile salt export pump: characterization of substrate specificity and identification of inhibitors. Gastroenterol 2002; 123:1649-58.

5. KapanoffD.E., Snider D., Caras G., Isoniazid related hepatitis: a U.S. Public Health Service cooperative surveillance study. Am Rev Respir Dis 1979; 117:991-1001.

6. Grosset J, Leventis S. Adverse effects of rifampin. Rev Infect Dis 1983; 5:S440-S50. 
7. Dossinth M. Wilcke J.T., Askgard D.S., Nybo B., Liver injury during ant tuberculosis treatment: an 11-year study. Tuber Lung Dis 1996; 77:335-40.

8. Hawang SJ, Wu JC, Lee CL, Lin TP, Lee SD. A prospective clinical study of isoniazid-rifampicin-pyrazinamide-induced liver injury in an area endemic for hepatitis B. J Gastroenterol Ther 1997; 12:87-91.

9. Teleman MD, Chee C.B., EarnestA., Wang Y.T. Hepatotoxicity of tuberculosis chemotherapy under general program conditions in Singapore. Int J Tuber Lung Dis 2002; 6:699705.

10. O Brien R.J, Long M.W., Cross F.S., Lyle M.A., Sider D.E. Jr., Hepatotoxicity from isoniaxid and rifampicin among children treated for tuberculosis. Pediatrics 1983; 72:491-499.

11. Ormerod L.P, Horsfeld N, Frequency and type of reactions to anti-tuberculosis drugs observations in routine treatment. Tuber Lung Dis 1996; 77:37-42.
12. Shakya R, Rao B.S., Shrestha B. Incidence of hepatotoxicity due to anti-tubercular medicines and assessment of risk factors. Ann Pharmacother. 2004; 38:1074-1079.

13. Capelle P., Dhumeaux D., Mora M., Feldman G., Berthelot P., Effect of rifampicin on liver function in man. Gut 1972; 13:366-71.

14. Larrey D., Epidemiological individual susceptibility to adverse drug reactions affecting the liver. Semin Liver Dis 2002; 22:145-55

15. Benichou C. Criteria for drug-induced liver disorder: report of an international consensus meeting. J Heptol 1990; 11: 272-27. 